\title{
"BARRIERS-TO-CHANGE" IN A GOVERNMENTAL SERVICE DELIVERY TYPE ORGANISATION
}

\author{
CJH COETZEE \\ KAREL J STANZ \\ karels@uj.ac.za \\ Department of Human Resource Management \\ University of Johannesburg
}

\begin{abstract}
Very little empirical research has been conducted within the South African context and internationally in assessing barriers-to-change specifically. The intended outcome of this research was to develop a framework for proactive change management. A sample of convenience was utilised with 332 respondents. The Barriers-to-Change Questionnaire, developed for and utilised during this study, exists out of 92 items, posted in question format anchored at the extreme sides. The results yielded a single scale with a Cronbach Alpha of 0.983. It is concluded that the domain of "Barriers-to-Change" was successful measured. The findings and their implications are also discussed.
\end{abstract}

Keywords:

Change in management, resistance to change, barriers to change

\section{Change}

One of the principal reasons people form organisations is to focus attention and energy on a selected goal - this goal being the provisioning of products and/or services to clients. Due to forces demanding change, organisations are required to change to be able to continue their existence, making change unavoidable and part of the organisation's life cycle.

Organisations, because of external and internal forces for change, are changing globally. Weiss (2001) states that a survey of 12000 managers in 25 countries indicated international expansion, reduction in employment, mergers, disinvestures, acquisition and major restructuring as the types of changes they have experienced in the immediate past. Pendlebury, Grouard and Mestan (1998), state that no business can escape the need for change as it evolves in the context of a rapidly changing environment. Organisations can either instigate change or submit to change, but to be able to stay in business they will have to change, one way or the other.

\section{Change Management}

Change, according to Robbins (1993), is concerned with making things different and change management, with change interventions, are planned actions to make things different. However, employee resistance can be a significant deterrent to effective organisational change, because organisational change can generate scepticism and resistance in employees, sometimes making it difficult or impossible to implement organisational improvements (Folger \& Skarlicki, 1999; Schumacher (2003).

Thus the premise that if change is unavoidable, it needs to be managed to serve the best interests of the organisation, therefore the need for change management arises. This view is supported by Pendlebury, et al. (1998) who states that although change is important for organisational survival it causes destabilisation of the organisation as it is now, and therefore it is important to manage this change; making change a management issue. However, the issue is HOW to manage such change (Govender, Moodley \& Parumasur, 2005).

The change problem is identified by Ackerman (1986), ProSci (1998), Nichols (2000) and Meyer and Botha (2000) as a current ("as-is") state to be left behind, a future ("to-be") state to be realised and the structured, organised process for moving from the one to the other. Fundamental to the change problem lies the reality that people tend to resist change and the issue of measuring for change management intervention purposes.

\section{Resistance to Change}

Resistance to change has long been recognised as a critically important factor that can influence the success or failure of any organisational change effort (Waddal \& Sohul, 1998; ProSci, 1998). Research indicates that $50 \%$ to $75 \%$ of all major corporate change efforts fail and that resistance is the "little-recognised but critically important contributor" to that failure (Waddal \& Sohul, 1998).

In researching resistance to change it became evident that researchers concur that there is such a factor as resistance to change, which is embodied in barriers-to-change (Mariotti 1998; Maurer, 2003). Resistance to change is identified as the employee response (behaviour) to the treatment employees receives in the change process and to managerial control. Resistance is employee behaviour that seeks to challenge, disrupt, stop, re-route or invert prevailing assumptions, discourses, and power relations (Folger \& Skarlicki, 1999; Van Tonder 2004). This very much implies that resistance to change is "negative", which is not necessarily true. It could be that employees know something about intended change that the implementers thereof do not know, and therefore resist change to avert possible negative effects.

Resistance to change, however, does not wait for change management to be implemented before it shows itself. The moment there are indicators of change on the organisational horizon, resistance to change will show itself in one or many ways (Kreitner \& Kinicki, 2004).

The problem pertaining to change management is that barriersto-change are evident in all changing environments, with various levels of understanding and acceptance about the issue of resistance to change. People understand, react to and view change in the workplace in different ways, some thrive on it and see it as a challenge, while others view it with suspicion and fear (The National Academy's January 2000 Workshop).

According to CS Research Services (2003) people at different levels in the organisation treat change differently. Young (2000) indicates that change efforts to redefine jobs and replace highly skilled and experienced workers with less skilled and fewer people increase the likelihood of managerial resistance. The author strongly support Appelbaum, St-Pierr and Glavas (1998), in stating that there is a misconception that managers do not resist change and that resistance only comes from operative employees. Resistance of middle and first-line managers is often identified as a major implementation barrier. 
Resistance to change is, unfortunately, not a one-dimensional concept. It is equally important to understand the different dimensions of resistance, who will resist change and how change is resisted.

\section{Barriers-to-Change}

Resistance to change manifests itself in barriers-to-change, but the management of barriers-to-change, however, need not to be re-active. Addressing barriers-to-change, Schumacher (2003) identifies barriers as severe, unexpected and not planned for problems in projects. Research done during the current investigation revealed that there is no integrated view on change and barriers-to-change; previous research either addresses the issue of barriers-to- change in a generic manner or focusses on a specific industry. No South African based study regarding barriersto-change could be found and no study that focuses specifically on a Governmental, service delivery type environment could be found. The following related research was found:

- The most recent research done in South Africa is the work of Govender, Moodley and Parumasur (2005), who focussed on identifying the critical ingredients for effective change management in institutions of higher education.

- Steward and Kringas (Online, 2005) from Centre for Research in Public Sector Management, University of Canberra stated that change is an ever-present theme in management literature, but empirical studies which seek to draw lessons from the experience of managing change are relatively rare.

- Szamosi and Duxbury (2002) developed and validated a measure of organisational support of revolutionary change, which identified nine unique behaviours that described three constructs.

The authors are of the opinion that the real problem regarding resistance and barriers-to-change is that management does not understand what barriers-to-change are and where they manifest in an organisation. If this is not understood and pro-actively planned for, the management of barriers-to-change will not be possible and therefore immediately decreases the possibility of implementing successful change. The premise is that if you know which barriers to expect, pro-active interventions can be launched to either nullify or minimise its effect.

\section{The Barriers-to-Change Matrix (BCM) and Barriers-to- Change Questionnaire (BCQ)}

In an effort to create a theoretical frame of reference that depicts the complexity of the change concepts, and from where a measuring instrument can be developed, the work of authors such as Tosi, Rizzo and Carrol (1996) and Schumacher (2003), as well as sources such as CS Research Services (2003) and ProSci (1998 en 2002) were utilised. The result of this was the Barriers-to-Change Matrix (BCM), which is depicted in Figure 1.

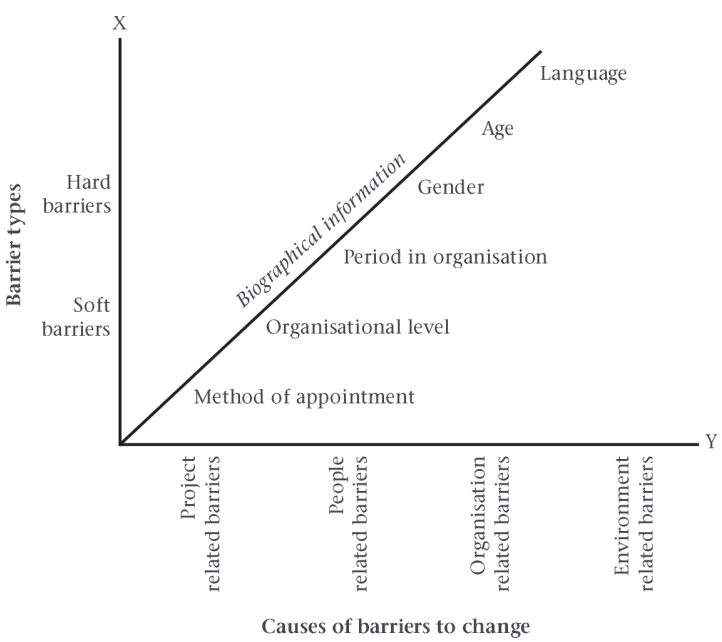

Figure 1: Barriers-to-Change Matrix
Integration of theory and practice led to an understanding that barriers-to-change could be categorised into four possible causes of barriers-to-change. These causes, being project related barriers, people related barriers, organisational related barriers and environment related barriers are plotted on the y-axis.

The $\mathrm{x}$-axis is utilised to plot barriers types, which are fixed (for purposes of this study) as hard and soft barriers. As this study's scope is to focus on barriers-to-change, no further attention was given to this axis and other possibilities that could be included.

To be able to make information regarding barriers-to-change (obtained through a questionnaire) specific enough to plan a change intervention on, the z-axis contains the biographical variables that were included in the BCQ.

The BCM and the integration of theory serves the purposes of providing a framework from where barriers-to-change could be understood, explained and managed as well as providing a firm base from where the BCQ could be developed to measure which barriers-to-change is evident in a specific environment.

The $\mathrm{BCM}$ and the research done in the development of the $\mathrm{BCM}$ was utilised to develop the BCQ. The BCQ is the measurement instrument utilised to obtain empirical data for statistical analysis. The BCQ served the purpose of a theoretical model and with the administration thereof, an empirical model could be constructed.

\section{Objectives of the Study}

The primary objective of this study was to create a theoretical frame of reference for the interrelated concepts of change, change management and barriers-to-change. The secondary objectives of the literature review were:

- To discuss the interdependencies between the concepts of change, change management and barriers-to-change.

- To review research done on barriers-to-change with the purpose of creating an integrated barriers-to-change, theoretical, model.

- To develop a Barriers-to-Change Matrix (BCM) and the identification of items for the Barriers-to-Change Questionnaire (BCQ).

The primary empirical research objective was to apply the developed BCM and BCQ to a Governmental service delivery type organisation with the purpose of determining which barriers-to-change is evident in such an environment. The secondary empirical research objectives were:

- To develop a questionnaire with high metric characteristics. - To identify the underlying factor structure of the BCQ.

- To determine the Reliability of the BCQ and the BCQ sub scales

- To analyse and interpret the differences between biographical variables and the BCQ.

- To prioritise barriers-to-change according to the responses of the participants in order to enable the identification of specific change management focus areas.

The objective is to determine, in particular, which barriers-tochange are applicable to a Governmental service delivery type organisation.

\section{Hypotheses}

One hypothesis with nine sub-hypotheses were formulated:

- Hypothesis 1: There is no statistically significant difference between certain biographical variables and barriers-tochange.

- Sub-hypothesis 1.1: There is no statistically significant difference between gender and barriers-to-change.

- Sub-hypothesis 1.2: There is no statistically significant difference between organisational level and barriers-to-change.

- Sub-hypothesis 1.3: There is no statistically significant difference between the period in the organisation and barriers-to-change. 
- Sub-hypothesis 1.4: There is no statistically significant difference between the age and barriers-to-change.

- Sub-hypothesis 1.5: There is no statistically significant difference between language and barriers-to-change.

- Sub-hypothesis 1.6: There is no statistically significant difference between the respondents FSE and barriers-tochange.

- Sub-hypothesis 1.7: There is no statistically significant difference between FSE's and barriers-to-change subdimensions.

- Sub-hypothesis 1.8: There is no statistically significant difference between language and barriers-to-change subdimensions.

- Sub-hypothesis 1.9: There is no statistically significant difference between FSE, language and barriers-to-change subdimensions.

Based on the fact that no evidence in the relevant literature could be found to support the relationship between different biographical variables (unit, organisation level, period in the organisation, gender, age, home language) and barriers-to-change, the above hypotheses were stated in a non-directional way.

\section{RESEARCH DESIGN}

\section{Research approach}

The following research design was decided upon to gain insight into barriers-to-change in a Governmental service delivery type environment.

- Exploratory, quantitative research. This was to allow for the exploration of a new area (barriers-to-change) where the results can provide significant insight into a given situation (Wikipedia, 2005), while allowing for the testing of hypotheses and the generalisation of data to the population (Huysamen, 1997; Chappel, 2005 \& Hopkins, 2005).

- Ex post facto research. Ex post facto research is aimed at the discovery of possible causes for behaviour (Watson, 2005).

- Primary and secondary data was used in this research (Culbert, 2005).

- Survey research. The method of information collection was the distribution of a questionnaire to the target organisation.

\section{Research Method}

Participants and sampling procedure

The population for this study consisted of individuals distributed over four organisational layers (being senior management, middle management, supervisory management and operational staff).

The target organisation was a Governmental service delivery type organisation. This organisation consists of 15 business units (also known as force structure elements or FSE's) and was at the time of this study in the midst of a change process.

The research study obtained 332 useable responses from 3700 employees. It was difficult to determine an accurate response rate for the BCQ as only thirteen original copies were provided to directors and the business unit managers for distribution and voluntary participation in the study. 375 Questionnaires were returned in hard copy as a result. Of the 375 completed questionnaires received, 332 could be utilised for the purpose of statistical analysis and 43 questionnaires were discarded.

\section{Measuring instrument}

In the absence of an established instrument on barriers-tochange, the measuring instrument (BCQ) was developed based on the literature review and addressed four dimensions, with relevant sub-dimensions. Each sub-dimension was populated by a number of items. Each item clearly required from the respondent to make a value decision on how he/she felt about that specific item according to a prescribed response scale. Table 1 depicts the BCQ dimensions and sub-dimensions.
TABLE 1

BCQ DIMENSIONS

\begin{tabular}{|c|c|c|}
\hline Serial No & Dimension & Sub-dimensions \\
\hline \multirow[t]{4}{*}{1} & \multirow{4}{*}{$\begin{array}{l}\text { Project Related } \\
\text { Barriers }\end{array}$} & Direction Clarity / Uncertainty \\
\hline & & Planning of Project \\
\hline & & Implementation of the Project \\
\hline & & Control of the Project \\
\hline \multirow[t]{8}{*}{2} & \multirow{8}{*}{$\begin{array}{l}\text { People Related } \\
\text { Barriers }\end{array}$} & Status Quo \\
\hline & & $\begin{array}{l}\text { Resistance because of the Change Itself/ } \\
\text { Change Fatigue/A belief that the Change does } \\
\text { not make Sense }\end{array}$ \\
\hline & & Understanding of the Change/Uncertainty \\
\hline & & Ability to Change (Tolerance) \\
\hline & & Leadership/Management \\
\hline & & Fear of Losing Something of Value \\
\hline & & Commitment Barriers \\
\hline & & General People Barriers \\
\hline \multirow[t]{7}{*}{3} & \multirow{7}{*}{$\begin{array}{l}\text { Organisation } \\
\text { Related Barriers }\end{array}$} & Direction Clarity \\
\hline & & Structure and Interdependency Barriers \\
\hline & & Customer Satisfaction Barriers \\
\hline & & Communication Barriers \\
\hline & & Process and System Barriers \\
\hline & & Skills Related Barriers \\
\hline & & Ability to Change Barriers \\
\hline 4 & $\begin{array}{l}\text { Environment } \\
\text { Related Barriers }\end{array}$ & Environment Related Barriers \\
\hline
\end{tabular}

The measurement instrument consisted of the different parts. These parts represented an introductory letter from the head of the target organisation, the biographical part of the questionnaire, the questionnaire's completion instructions, the actual questionnaire with a total of 93 items, and space for additional comments.

\section{Biographical variables}

Very little research could be found that addressed the issue of which biographical variables or characteristics to include in studies regarding individual behaviour and change. Using Robbins (1993); Szamosi and Duxbury (2001) as points of departure, unit or directorate, method of appointment, organisational level, period in the organisation, gender, age and home language were included for this purpose.

\section{The Response Scale}

A six point Likert type response was used in the BCQ with each question anchored at both sides to limit response uncertainty, not making provision for a neutral or undecided option (Thiessen, 1993). Table 2 depicts the response scale used in the study.

TABLE 2

Response SCAle EXample

\begin{tabular}{|c|c|c|c|c|c|c|c|}
\hline \multirow{2}{*}{$\begin{array}{l}\text { Item } \\
\text { No } \\
\end{array}$} & \multirow{2}{*}{$\begin{array}{l}\text { Question } \\
\text { To what extent } \\
\text { does the } \\
\text { vision of your } \\
\text { organisation } \\
\text { embrace } \\
\text { organisational } \\
\text { diversity? }\end{array}$} & $\begin{array}{l}\text { Statement } \\
\mathbf{1}\end{array}$ & & \multicolumn{3}{|c|}{ Rating Scale } & \multirow{2}{*}{$\begin{array}{l}\text { Statement } \\
2 \\
\text { Embrace } \\
\text { very much. }\end{array}$} \\
\hline & & $\begin{array}{l}\text { Embraces } \\
\text { nothing. }\end{array}$ & 1 & 23 & 45 & 6 & \\
\hline
\end{tabular}




\section{Research Procedure}

The normal channels of command and control was utilised to ensure that required protocol was adhered to and that there would not be unnecessary resistance to the research.

The pilot study entailed the following:

- The head of the target organisation approved the research in person and indicated at his command conference that this research would be done.

- To ensure face validity the BCQ were discussed with the target organisation's second-in-command, a professor and other specialist at a local university, as well as with two senior members of the target organisation. Inputs were received and accommodated.

The field survey entailed the following:

- The BCQ was provided in hard copy to directors and business unit managers with a covering letter from the head of the target organisation explaining that it was an organisation wide survey and what the purpose was.

- To ensure unbiased responses the respondents did not see the dimensions and sub-dimensions of the questionnaire, they only responded to 93 items.

- The questionnaires were completed during a normal weekly FSE meeting and handed in when the respondents were finished. As responses were voluntary, only completed questionnaires were retrieved.

- Contact persons at the participating organisations were asked to ensure responses from all four levels of the organisation as well as ensuring the completeness of the questionnaires.

- Questions regarding the completion of the questionnaires were made to the author personally and completed questionnaires were forwarded to the author directly.

\section{Statistical analysis}

The responses of the completed questionnaires were provided to STATCON of University of Johannesburg who did the statistical analysis, using the SPSS statistical package. The statistical analysis was conducted in two phases.

Phase One focussed on data analysis to provide proof that the measuring instrument is reliable and valid for the purpose of this study. The following analysis was included in Phase One:

- Sample Statistics. Frequency analysis was utilised to describe the sample obtained (Kerlinger, 1992).

- Cross Tabulations. Cross tabulations were utilised to explain the biographical variables per FSE.

- Item Descriptive Statistics. Item descriptive statistics were utilised to determine the normality of the item distribution.

- Factor Analysis. The BCQ was factor analysed according to the procedure suggested by Schepers (1992) in order to determine the factor structure of the instrument. To determine the adequacy and sphericity of the intercorrelation matrix the Kaiser-Meyer-Olkin (KMO), Measure of Sampling Adequacy (MSA) and the Bartlett's Test of Sphericity were conducted.

- Reliability analysis. A reliability analysis was conducted on the BCQ and its sub-scales with the purpose of calculating a reliability coefficient (Cronbach Alpha).

- Descriptive statistics (mean and standard deviation) on the identified reliable theoretical factors of the total sample.

Phase Two focussed on the testing of hypotheses by means of the following inferential statistical methods:

- T-tests were used when there were only two variables that need to be considered.

- ANOVA (one-way analysis of variance) calculations were used for the one-way fixed factor analysis.

- MANOVA (multivariate analysis of variance) was used when there was more than one dependent and independent variables (Kerlinger, 1992).

- Effect size (eta) of difference in means for all independent variables was calculated (Coe, 2000; Becker, 2004 \& Cook, 1999)

\section{RESULTS}

With the development of the BCM and the BCQ the primary and secondary literature review objectives were achieved, with the BCQ enabling the empirical research.

The empirical findings are discussed according to the analysis methodology. Phase One deals with the descriptive statistics, factor analysis and reliability analysis. Phase Two deals with the results of the inferential statistical procedures and the testing of the hypothesis.

\section{Phase One: Empirical Findings}

Descriptive statistics. The BCQ indicated that most item distributions had a close to normal distribution as the means, medians and modes were relatively close to one another (Kaplan, $1987 \&$ Schepers, 1992).

The composition of the sample is presented in Table 3. Due to insignificant returns from eleven force structure elements (FSE's), their responses were grouped into FSE 1 and FSE 2.

TABLE 3

Frequency Table of Participating Organisations of the ObTained SAMPLE

\begin{tabular}{lccc}
\hline & Frequency & Percent & $\begin{array}{c}\text { Cumulative } \\
\text { Percent }\end{array}$ \\
\hline FSE 1 & 39 & 11,7 & 11,7 \\
FSE 2 & 72 & 21,7 & 33,4 \\
FSE 3 & 68 & 20,5 & 53,9 \\
FSE 4 & 88 & 26,5 & 80,4 \\
FSE 5 & 65 & 19,6 & 100,0 \\
Total & 332 & 100,0 & \\
\hline
\end{tabular}

Factor analysis. After the first order factor analysis on the BCQ was done, it was established that there are only one underlying factor and therefore a second order factor analysis was not done (Hair, et al., 1998; Gregory, 1996; Schepers, 1992; Kaplan, 1987; Kerlinger \& Lee, 2000: Kerlinger, 1992; Allen \& Yen, 1979). The following forms of validity are relevant to the BCQ:

- Construct validity. It is concluded that the BCQ measured what it was designed to measure.

- Factorial validity. The first order factor analysis extracted only one factor which explained $40.126 \%$ of the variance.

- Content validity. The sampling adequacy of the BCQ was established by the KMO measure for sampling adequacy and the Bartlett's test for sphericity. It was established that the data set complies with the requirements of sampling adequacy and sphericity, and could thus be subjected to factor analysis.

According to Hair, et al. (1998) a result of 0.6 and higher is required from the MSA to be acceptable. From Table 4 it is clear that the data set complies with the requirements of sampling adequacy (0.956) and sphericity, and could thus be subjected to factor analysis.

\section{TABLE 4}

KMO AND BARTLETT's Test Results

\begin{tabular}{|c|c|c|}
\hline \multicolumn{2}{|c|}{$\begin{array}{l}\text { Kaiser-Meyer-Olkin Measure of Sampling } \\
\text { Adequacy }\end{array}$} & 0,956 \\
\hline \multirow[t]{3}{*}{ Bartlett's Test of Sphericity } & Approx. Chi-Square & 25692,343 \\
\hline & df & 4278 \\
\hline & Sig. p-value & 0,000 \\
\hline
\end{tabular}

Taken as a whole, an $8.6 \%$ sample of the target organisation was obtained. The sample had an acceptable distribution of respondent related properties and was a fair reflection of 
the characteristics of the actual population although slight deviations from the population strata exist. A $23.3 \%$ sample of senior management was obtained and a $6.3 \%$ sample of operational staff was obtained, which could be viewed as low, but in relation to the $8.6 \%$ sample on average, this is still acceptable.

Guilford and Fruchter (1978) explains the relationship between validity and reliability by stating that it can be accepted, as a principle, that the predictive validity of a test is directly proportional to its reliability, indicating that the more reliable the test, the more valid it is. The statistics regarding the reliability of the BCQ follows.

Reliability. The BCQ obtained a Cronbach Alpha Coefficient of 0.983 from 93 items. The BCQ sub-scales obtained the following reliability scores:

- Project related barriers-to-change. Cronbach Coefficient Alpha $=0.945$

- People related barriers-to-change. Cronbach Coefficient Alpha $=0.953$.

- Organisation related barriers-to-change. Cronbach Coefficient Alpha $=0.972$.

- Environment related barriers-to-change. Cronbach Coefficient Alpha $=0.837$.

Table 5 depicts the reliability statistics from the mentioned reliability analysis and indicates a Cronbach Alpha Coefficient of 0.983 from 93 items.

TABLE 5

Reliability Statistics

\begin{tabular}{cc}
\hline Cronbach's Alpha & N of Items \\
\hline 0,983 & 93 \\
\hline
\end{tabular}

The Cronbach Alpha coefficients indicate that the BCQ have acceptable reliability, can consistently measure the particular dimensions of the magnitude it is designed to measure and indicates a high degree of homogeneity between the questionnaire items (Kaplan, 1987; Kerlinger, 1992 \& Cortina, 1993).

Normality. In order to determine the normality of the scale obtained in the factor analysis, the KolmogorovSmirnov test was performed. Table 6 indicates that the scale conforms to normality. The Z-statistic is 0.658, being greater than 0.05 means that the scale is normally distributed. Unlike most statistical testing, a non-significant result is sought after here.

\section{TABLE 6}

ONE-SAMPLE Kolmogorov-SMIRnOv TeST FOR THE BCQ

\begin{tabular}{llc}
\hline & & $\begin{array}{c}\text { Barriers-to-change } \\
\text { (ALL) }\end{array}$ \\
\hline $\mathrm{N}$ & & 320 \\
Normal Parameters(a,b) & Mean & 3,4442 \\
& Std. Deviation & 0,87521 \\
Most Extreme Differences & Absolute & 0,037 \\
& Positive & 0,035 \\
& Negative & $-0,037$ \\
Kolmogorov-Smirnov Z & & 0,658 \\
Asymp. Sig. (2-tailed) & & 0,779 \\
\hline
\end{tabular}

a Test distribution is Normal

b Calculated from data
Due to the high reliability score of the $\mathrm{BCQ}$, it could be used to test the hypotheses presented in Phase Two.

\section{Phase One: Empirical Findings}

The hypothesis that forms the basis for this study is; "there is no statistically significant difference between the different biographical variables (unit, organisation level, period in the organisation, gender, age, home language) and barriers-to-change".

The findings, regarding the above-mentioned biographical variables, as described in sub-hypothesis 1.1 to 1.6 , indicated the following:

- The gender, organisational level, period and age biographical variables indicated no statistically significant differences regarding their experiences of barriers-to-change.

According to the secondary empirical research objectives the mentioned biographical variables can therefore not be used to identify specific change management focus areas.

- The variables of language and FSE, however, indicated that there are statistically significant differences regarding their experiences of barriers-to-change.

According to the secondary empirical research objectives these two variables can serve as specific change management focus areas.

- However, further analysis revealed that very small effect sizes were obtained, and therefore sub-hypotheses 1.1 to 1.6 are accepted, implying that there is no statistically significant difference between the respective biographical variables and barriers-to change.

Due to the initial indication that language and FSE had statistically, significant differences regarding their experiences of barriers-to-change, it was decided to execute further analysis on these two variables in the context of the BSQ subdimensions.

Sub-hypotheses 1.7 to 1.9 postulated that there were no statistically significant difference between (1.7) FSE's, (1.8) language and (1.9) FSE's \& language and the barriers-tochange sub-dimensions. The statistical analysis, however, indicated that there are no statistically significant difference between mentioned variables and the barriers-to-change subdimensions.

\section{Implications of the analysis}

Factor analysis. The first order factor analysis extracted only one factor. At first glance it could be interpreted that the theoretical model, which indicates four sub-dimensions for barriers-to-change, could be wrong and is in conflict with the empirical model, which indicates only one factor. It is however suggested that this is not wrong and should be viewed from two perspectives:

- The first perspective is from a theoretical and managerial point of view. This research clearly indicated that barriers-tochange can be grouped into four sub-dimensions for purposes of clarity and manageability. It is therefore concluded that the theoretical model (BCM) is correct.

It is important, for management, to understand which dimension of barriers-to-change needs attention. It also provides management with a theoretical model to plan for the management of barriersto-change.

- The second perspective is that of the people who is going through the change process. In this instance people will not think about the aspects that cause them "pain" as a barrierto-change within a specific sub-dimension, they merely see and experience "things" that are "threatening" their current existence. As a result, the empirical model depicts only one factor. 
The reason for extracting only one factor from the BCQ data lies in the experience of people; people experience change, not sub-dimensions of change; therefore the high correlation of scores.

Hypotheses. The results of the study indicated that all of the biographical variables utilised in this study show that there is no statisticalsignificant difference between the biographicalvariables and barriers-to-change, as well as between the biographical variables and the barriers-to-change sub-dimensions.

Meeting of objectives. In terms of meeting the secondary empirical objectives, it was concluded that the following secondary empirical objective were not met:

- To prioritise barriers-to-change according to the responses of the participants in order to enable the identification of specific change management focus areas.

\section{DISCUSSION}

The results of the analysis indicate the following:

- The BCM, from a theoretical and management point of view, provides a sound theoretical model which suggests focus areas from which change interventions can be planned and executed. This model can be used during the design phase of organisational change, thus managing change proactively, or reactively, once resistance to change is experienced.

- The BCQ is valid and reliable for use in a Governmental service delivery type organisation.

- The barriers-to-change sub-dimensions can serve as a basis for the management of barriers-to-change. The research also indicated that none of barrier-to-change sub-dimensions can be viewed as more important than the other.

- None of the biographical variables investigated indicated that it makes the experience of change different. None of these biographical variables can therefore be utilised to serve as a barriers-to-change focus area.

This research has theoretical, practical, and methodological significance as it contributes to the better understanding of barriers-to-change in theory and in practice by applying it in a Governmental service delivery type organisation.

- This study adds to the body of knowledge regarding the management of change, and specifically, the management of barriers-to-change. This is significant based on the statement of Steward and Kringas (Online, 2005), which indicated that change is an ever-present theme in management literature, but empirical studies which seek to draw lessons from the experience of managing change are relatively rare.

- The insight gained into the various aspects of barriersto-change will contribute to theory building and the more accurate assessment of barriers-to-change. This will assist managers to design and implement effective change interventions, which will enhance the probability of change to be successful.

- This research comprehensively contributes to the body of knowledge of organisational development, organisational behaviour and change management, providing a quantitative method (the BCQ) for assessing barriers-to-change. This is valuable because very little empirical research has been conducted, both internationally and in South Africa, to assess barriers-to-change specifically.

- This research provides evidence that barriers-to-change do exist, that it can be grouped into specific dimensions (theoretical model) for management purposes, and that people do experience change. People, however, do not experience change as it is suggested in the theoretical model; they experience change and its "pain" in a holistic manner.

A significant limitation of the study is that the results of this study can only be generalised to the population of the target organisation and to other similar environments.
A suggestion that may improve the methodology used is that the six point Likert type response scale used in this study should be further refined to improve the reliability and validity of responses. Due to the complexity of the issue at hand, the depth of the questionnaire and the fact that the questionnaire was administered at all organisational levels, it is suggested that at selected items, a "do not know" option should be provided. This could be necessary where respondents, due to a specific biographical variable (such as position in the organisation), will not have sufficient information to answer "correctly" (example: "Is the project adequately resourced?" At lower organisational levels it is possible that respondents could have no insights into the resources provided to neither the project, nor the number of resources required).

Considering the scope and complexity of this study area several recommendations were made from theoretical, methodological and practical perspectives. Within the framework of this study the following suggestions for potential research opportunities are made:

- A comparison between different Governmental service delivery type organisations should be made, with the purpose of generalising findings.

- A comparison between Governmental service delivery type organisations and for-profit organisations should be made, with the purpose of generalising findings.

- Further research could be undertaken to enhance the $\mathrm{x}$-axis (indicating barrier types) of the BCM.

- Further research could be undertaken to develop a model and questionnaire that specifically addresses the environmental barriers-to-change sub-dimension of the BCM.

The findings of this study do not only provide valuable insights into the theory of organisational change, change management and barriers-to-change, thereby contributing to the body of knowledge, but also provide insight into the management of barriers-to-change.

\section{CONCLUSION}

The study of barriers-to-change is a relatively new field of study and many gaps still exist in the body of knowledge. Organisational change, change management and barriersto-change are an encompassing, multifaceted construct, characterised by a myriad of dimensions and perspectives. It permeates all aspects of organisational life and has become a popular field of study because of the promises it holds for continued organisational existence and improvement of organisational performance.

In conclusion, the management of barriers-to-change is a strategic issue. He who discounts it as just another people issue will live to experience the results of his/her erroneous thinking. On the other hand, he who realises its importance, might just "live" to do business another day.

\section{REFERENCES}

Ackerman, L. (1986). Development, Transition or Transformation: The Question of Change in Organizations. OD Practitioner, December 1986, pp. $1-8$.

Allen, M.J. \& Yen, W.M. (1979). Introduction to Measurement Theory. Montery, CA: Brooks/Cole Publishing Company.

Appelbaum, S.H., St-Pierre, N., \& Glavas, W. (1998). Strategic organisational change: The role of leadership, learning, motivation and productivity. Management Decision, 36 (5), pp. $289-301$.

Becker, L. (2004). Effect Size (ES). University of Colorado at Colorado Springs. Retrieved from the World Wide Web, http://davidmlane.com on 24 November 2004. 
Coe, R. (2000). What is an "Effect Size'? A Guide for Users. Retrieved from the World Wide Web, http://www.davidmlane.com on 22 April 2005.

Cook, L.B. (1999). Effective Uses of 'Effect Size' Statistics to Demonstrate Business Value. Quirk's Marketing Research Review, Article Number 0518, October 1999.

Cortina, J.M. (1993). What is Coefficient Alpha? An Examination of the Theory and Applications. Journal of Applied Psychology, 78(1), 98,104.

Chappel, C. The Nature of Quantitative Research. Retrieved from the World Wide Web, http://www2.gsu.edu on 22 April 2005.

CS Research Services. (2003). Plan a Campaign to Tackle the Barriers to Change. Retrieved from the World Wide Web, http://www.cscresearchservices.com on 29 January 2003.

Culbert, J. Sources and Uses of Data. RMS - the Research Methods Server in the Division of Social Sciences, School of Law and Social Sciences, Glasgow Caledonian University. Retrieved from the World Wide Web, http://www.oassis.gcal.ac.uk, on 22/04/2005.

Folger, R. \& Skarlicki, D.P. (1999). Unfairness and Resistance to Change: Hardship as Mistreatment. Journal of Organizational Change Management, Vol. 12, No 1, 1999, pp. 35-50.

Govender, P., Moodley, S. \& Parumasur, S.B. (2005). The Management of Change at Selected Higher Education Institutions: An Exploration of the Critical Ingredients for Effective Change Management. SA Journal of Industrial Psychology, 2005, Vol. 31 (1), pp. 78 - 86.

Gregory, R.J. (1996). Psychological Testing. History, Principles, and Applications. ( $2^{\text {nd }}$ Edition) Allyn and Bacon, Boston.

Guilford, J.P. \& Fruchter, B. (1978). Fundamental Statistics in Psychology and Education. (6 ${ }^{\text {th }}$ Edition) McGraw-Hill Book Co, Singapore.

Hair, J.F. Jr., Anderson, R.E., Tatham, R.L. \& Black, W.C. (1998). Multivariate Data Analysis. (5 ${ }^{\text {th }}$ Edition) Upper Saddle river, NJ: Prentice-Hall International.

Hopkins, W.G. (2005). Quantitative Research Design. Department of Physiology and School of Physical Education, University of Otago, Dunedin, New Zealand, 9001. Retrieved from the World Wide Web, http://www.sportsci.org on 23 April 2005.

Huysamen, G. K. (1997, March). "Parallels Between Qualitative Research and Sequentially Performed Quantitative Research." South African Journal of Psychology, Vol. 27, pp. 1 - 8.

Kaplan, R.M. (1987). Basic Statistics for Behavioral Sciences. Boston: Allyn and Bacon, Inc.

Kerlinger, F.N. (1992). Foundations of Behavioral Research. (3 ${ }^{\text {rd }}$ Edition) Harcourt Brace College Publishers.

Kerlinger, F.N. \& Lee, H.B. (2000). Foundations of Behavioural Research. ( $4^{\text {th }}$ Edition) New York: Harcourt College Publishers.

Kreitner, R. \& Kinicke, A. (2004). Organizational Behaviour. (6 th $^{\text {th }}$ Edition) McGraw Hill, Boston.

Mariotti, J. (1998). The Challenge of Change. Industry Week, Vol. 247 (7), p. 140

Maurer, R. (2003). Why Resistance Matters. http://www.refresher. com on 8 February 2003.

Meyer, M. \& Botha, E. (Editors) (2000). Organisation Development and Transformation in South Africa. Butterworth Publishers.

Nichols, F. (2000). Change Management 101: A Primer. Retrieved from the World Wide Web, http://www.home.att.net on dated 3 February 2003.
Pendlebury, J., Grouard, B. \& Meston, F. (1998). The Ten Keys to Successful Change Management. John Wiley \& Sons, Chichester.

ProSci (1998). Best Practices in Managing Change. Retrieved from the World Wide Web, http://www.prosci.com on 20 November 2000.

ProSci (2002). Change Management Overview and Introduction. Retrieved from the World Wide Web, http://www.ProSci com on 13 November 2002.

ProSci. (2002). Project Lessons - Critical Lessons Learned From 327 Project Teams. Retrieved from the World Wide Web, http:// www.prosci.com on 15 May 2003.

ProSci. (2002). Top reasons for change resistance - 288 companies reporting. Retrieved from the World Wide Web, http://www. prosci.com on 26 January 2003.

Robbins, S.P. (1993). Organizational Behavior. Concepts, Controversies and, Applications. (6 $6^{\text {th }}$ Edition) Prentice Hall, Englewood Cliffs, New Jersey.

Schepers, J.M. (1992). Toetskonstruksie: Teorie en Praktyk. Johannesburg: RAU Drukpers.

Schumacher, W.D. (2003). Overcoming Barriers to Change. Retrieved from the World Wide Web, http://www.itstime. com on 29 May 2003.

Schumacher, W.D. (2003). Managing Barriers to Business Reengineering Success. BPR Online Learning Center. Sponsored by ProSci. Retrieved from the World Wide Web, http://www. prosci.com on 15 May 2003.

Stewart, J. \& Kringas, P. (2005). Change Management - Strategy and Values. Six case studies from the Australian Public Sector. Centre for Research in Public Sector Management, University of Canberra. Retrieved from the World Wide Web, www.blis. canberra.edu.au/ crpsm/research/pdf/stewartkringas.pdf on July 2005

Szamosi, L.T. \& Duxbury, L. (2002). Development of a Measure to Assess Organizational Change. Journal of Organizational Change Management. Vol. 15, No. 2, 2002, pp. $184-201$.

The National Academy's January 2000 Workshop. (2000). Leading Institutional Change: A National Workshop for College and University Teams. Retrieved from the World Wide Web, http://www.thenationalacademy.org on 28 January 2003.

Thiessen, V. (1993). Arguing with Numbers - Statistics for the Social Sciences. Halifax: Fernwood Publishing.

Tosi, H.L., Rizzo, J.R. \&. Carrol, S.J. (1999). Managing Organisational Behaviour. Blackwell Publishers. Mas.

Van Tonder, C.L. (2004). Organisational Change. Theory and Practice. Van Schaik Publishers, Pretoria.

Waddell, D. \& Sohal, A.S. (1998). Resistance: a Constructive Tool for Change Management. Management Decision, Vol. 36/8, pp. $543-548$.

Watson, J. (Dr). Research Designs. Retrieved from the World Wide Web, http://www.ecourse.amberton.edu on 22 April 2005.

Weiss, J.W. (2001). Organizational Behavior and Change. Managing Diversity, Cross-Cultural Dynamics, and Ethics. South-Western College Publishing, Ohio.

Wikipedia, the Free Encyclopedia (2005). Retrieved from the World Wide Web, http://en.wikipedia.org on 22 April 2005.

Young, A.P. (2000). "I'm just me"”. A Study of Managerial Resistance. Journal of Organizational Change Management, Vol. 13, No. 4, 2000, pp. 375 - 388 
REVIEW PANEL EDITION 33.2 (2007)

Prof L Booysen

Prof M Coetzee

Dr SC Coetzee

Prof F Crous

Prof $\mathrm{M}$ de Beer

Prof B Erasmus

Prof CB Fouché

Prof C Foxcroft

Ms S Goosen

Dr S Hodgson

Prof G Huysamen

Dr EJ Jacobs

Mr A Martin (Statistical Analyst)

Ms M May (Clinical Psychologist)

Dr P Nel

Ms CM O’Neil

Dr IF Potgieter

Prof CC Theron

Dr S Vosloo
UNISA

UNISA

UNISA

University of Johannesburg

UNISA

UNISA

Massey University (NZ)

Nelson Mandela Metropolitan University

Rhodes University

Norwich Union, UK

Professor Emeritus

Solplaatje Municipality

Cell C

UNISA

University of Stellenbosch

University of Kwa-Zulu Natal

Armscor

University of Stellenbosch

UNISA 